\title{
Subacute bacterial endocarditis caused by Cardiobacterium hominis: A case report
}

\author{
Davie Wong $\mathrm{MD}^{1}$, Julie Carson $\mathrm{MD}^{2,3}$, Andrew Johnson $\mathrm{MD}^{4}$
}

D Wong, J Carson, A Johnson. Subacute bacterial endocarditis caused by Cardiobacterium hominis: A case report. Can J Infect Dis Med Microbiol 2014;25(1):41-43.

Cardiobacterium hominis, a member of the HACEK group of organisms, is an uncommon but important cause of subacute bacterial endocarditis. First-line therapy is a third-generation cephalosporin due to rare betalactamase production. The authors report a case involving endovascular infection due to $\mathrm{C}$ hominis that initially tested resistant to thirdgeneration cephalosporins using an antibiotic gradient strip susceptibility method (nitrocephin negative), but later proved to be susceptible using broth microdilution reference methods (a 'major' error). There are limited studies to guide susceptibility testing and interpretive breakpoints for $\mathrm{C}$ hominis in the medical literature, and the present case illustrates some of the issues that may arise when performing susceptibility testing for fastidious organisms in the clinical microbiology laboratory.

Key Words: Cardiobacterium hominis; Etest; Infective endocarditis

\section{Une endocardite bactérienne subaiguë causée par le Cardiobacterium hominis : un rapport de cas}

Le Cardiobacterium hominis, qui appartient aux organismes du groupe HACEK, est une cause d'endocardite bactérienne subaiguë peu fréquente, mais importante. La céphalosporine de troisième génération en est le traitement de première ligne, en raison d'une rare production de bêta-lactamase. Les auteurs rendent compte d'un cas d'infection endovasculaire à $\mathrm{C}$ hominis qui a d'abord été considéré comme résistant aux céphalosporines de troisième génération d'après la méthode de susceptibilité par bandelette contenant un gradient d'antibiotique (négative à la nitrocéphine), mais qui s'y est révélé susceptible selon les méthodes de microdilution de référence (une erreur «majeure »). Peu de publications traitent des études pour orienter les tests de susceptibilité et les seuils d'interprétation du C hominis, et le présent cas démontre quelques problèmes qui peuvent surgir lors de tests de susceptibilité d'organismes difficiles à isoler au laboratoire de microbiologie clinique.

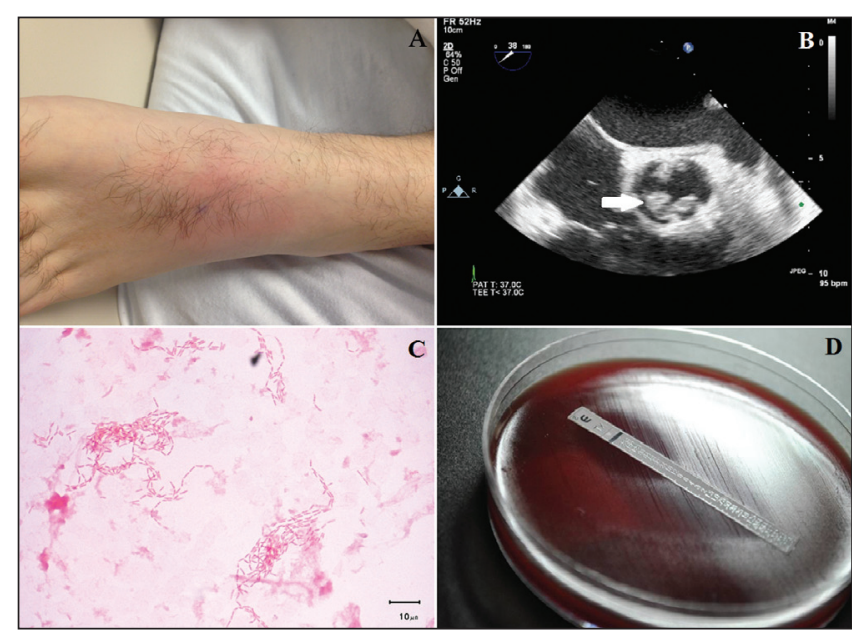

Figure 1) A Focal area of induration on dorsum of left foot. B Transesophageal echocardiogram (parasternal short axis view) demonstrating a bicuspid aortic valve with a large vegetation. C Gram stain of blood culture demonstrating Gram-negative bacilli consistent with Cardiobacterium hominis. D Etest (bioMérieux Canada, Inc) results for ceftriaxone with a double zone of inhibition at a minimum inhibitory concentration of $0.023 \mu \mathrm{g} / \mathrm{mL}$ and $16 \mu \mathrm{g} / \mathrm{mL}$. Bacteria within the intermediate zone of inhibition could not be cultured

and empirical therapy with intravenous vancomycin and ceftriaxone was initiated. Magnetic resonance angiography of the brain and a transesophageal echocardiogram were obtained. and erythrocyte sedimentation rate $28 \mathrm{~mm}$ (normal value $0 \mathrm{~mm}$ to $10 \mathrm{~mm}$ ). Three temporally distinct sets of blood cultures were obtained,

${ }^{1}$ Internal Medicine, University of Manitoba, Winnipeg, Manitoba; ${ }^{2}$ Section of Microbiology, Department of Pathology and Laboratory Medicine,

University of Calgary; ${ }^{3}$ Calgary Laboratory Services; ${ }^{4}$ Section of Infectious Diseases, Department of Medicine, University of Calgary, Calgary, Alberta

Correspondence: Dr Julie Carson, Calgary Laboratory Services, 9 - 3535 Research Road Northwest, Calgary, Alberta T2L 2K8.

Telephone 403-770-3338, e-mail julie.carson@cls.ab.ca 
TABLE 1

Summary of minimum inhibitory concentrations for Cardiobacterium hominis isolates

\begin{tabular}{|c|c|c|c|c|c|}
\hline \multirow[b]{2}{*}{ Antibiotic } & \multicolumn{3}{|c|}{ Minimum inhibitory concentration $(\mu \mathrm{g} / \mathrm{mL})$ by method and media } & \multicolumn{2}{|c|}{ CLSI interpretive criteria $(\mu \mathrm{g} / \mathrm{mL})$} \\
\hline & Etest-MHB & Etest-BBA & BMD-CAMHB-LHB* & Sensitive & Resistant \\
\hline Penicillin & 0.5 & $\leq 0.016$ & $\leq 0.06$ & $\leq 1$ & $\geq 4$ \\
\hline Ampicillin & 0.094 & 0.023 & $\leq 0.06$ & $\leq 1$ & $\geq 4$ \\
\hline Imipenem & 0.032 & 0.006 & No data & $\leq 0.5$ & $\geq 2$ \\
\hline Meropenem & 0.006 & $\leq 0.002$ & $\leq 0.06$ & $\leq 0.5$ & $\geq 2$ \\
\hline Ceftriaxone & 16 & 0.016 & $\leq 0.25$ & $\leq 2$ & - \\
\hline Levofloxacin & 0.012 & 0.008 & $\leq 0.25$ & $\leq 2$ & $\geq 8$ \\
\hline Trimethoprim-sulfamethoxazole & $0.094^{\ddagger}$ & $0.016^{\dagger}$ & $\leq 0.25 / 4.75$ & $\leq 0.5 / 9.5$ & $\geq 4 / 76$ \\
\hline
\end{tabular}

${ }^{*}$ Clinical Laboratory Standards Institute methodology (CLSI); ${ }^{\dagger}$ Amoxicillin concentration; ${ }^{\ddagger}$ Trimethoprim concentration. BMD Broth microdilution; BBA Brucella blood agar; CAMHB-LHB Cation-adjusted Mueller-Hinton broth with 5\% lysed horse blood; MHB Mueller-Hinton agar with $5 \%$ sheep blood

\section{DIAGNOSIS}

Transesophageal echocardiogram demonstrated a $1.7 \mathrm{~cm}$ vegetation on a previously unrecognized bicuspid aortic valve, with severe aortic insufficiency (Figure 1B). Magnetic resonance angiography of the brain revealed a focus of restricted diffusion in the corpus callosum, concerning for an infarct. By $48 \mathrm{~h}$, all blood cultures yielded a Gramnegative bacillus (oxidase positive, catalase negative and urease negative) identified as Cardiobacterium hominis (Figure 1C). The identification was confirmed by matrix-assisted laser desorption ionization time-of-flight (Vitek MS) and the Vitek NH identification card (bioMérieux Canada Inc, Canada). At the time of aortic valve replacement, both native aortic leaflets were markedly thickened and a perivalvular abscess was observed at the aortic valve root, which subsequently grew $\mathrm{C}$ hominis.

Initial Etest (bioMérieux Canada Inc) results, using MuellerHinton agar supplemented with 5\% defibrinated sheep blood (MHB), demonstrated resistance to ceftriaxone and cefotaxime (Figure 1D). The nitrocefin-based test (Nitrocefin SR112, Oxoid Microbiology Products, USA) for beta-lactamase production was negative. Subsequently, broth microdilution (BMD) in cation-adjusted MuellerHinton broth supplemented with 5\% lysed horse blood (CAMHBLHB) as well as Etest susceptibilities using Brucella blood agar (1) demonstrated susceptibility to all agents tested (Table 1).

\section{DISCUSSION}

Endovascular infection with $\mathrm{C}$ hominis, a member of the HACEK group of microorganisms (Haemophilus species, Actinobacillus actinomycetemcomitans, Cardiobacterium hominis, Eikenella corrodens and Kingella species), is usually insidious in onset, with a prolonged subacute course characterized by leukocytosis, anemia, splenomegaly, embolic phenomena, congestive heart failure and weight loss (2). Dental work (as well as routine oral hygiene/quality of dentition) and bicuspid aortic valve are both welldocumented risk factors for developing infective endocarditis due to HACEK microorganisms (2). Our patient typified these characteristics.

Although $\mathrm{C}$ hominis is of relatively low virulence, endovascular infection complicates $95 \%$ of all cases of bacteremia, with the aortic valve being most commonly affected $(3,4)$. Almost one-half of patients require valve replacement. Peripheral and central nervous system emboli occur frequently in $\mathrm{C}$ hominis endocarditis, noted in $51 \%$ and $21 \%$ of cases, respectively, especially when the aortic valve is involved $(3,5,6)$. Extravascular infection is unusual (7). Prognosis is generally favourable, with a $93 \%$ cure rate for both native and prosthetic valve infection (3). A third-generation cephalosporin is the drug of choice for infection with HACEK organisms (8).

In our patient, initial minimum inhibitory concentration determinations using Etest methodology on MHB agar demonstrated resistance to third-generation cephalosporins (nitrocephin negative). This complicated early management of the patient because it appeared to preclude the use of first-line therapy for Chominis endocarditis.
Repeat testing with Clinical and Laboratory Standards Institute (CLSI)-approved reference methods (1) demonstrated susceptibility to third-generation cephalosporins. We were unable to reproduce this 'major' error with other recent $\mathrm{C}$ hominis isolates $(\mathrm{n}=5)$ in our laboratory (data not shown).

Penicillin resistance due to beta-lactamase production has been documented in C hominis $(9,10)$, but cephalosporin resistance has only been described in a single case report (9) based on disc diffusion testing. Guidelines for susceptibility testing of fastidious organisms, including the HACEK group, are relatively new (1). For Cardiobacterium species, the recommended testing method is BMD in CAMBH-LHB (as for pneumococcus and other fastidious organisms). Although not endorsed by CLSI, many laboratories use Etest or other gradient strip methodologies for ease of use and accessibility. In the present case, use of a non-CLSI-approved antibiotic gradient strip susceptibility testing methodology resulted in a 'major' error. The risk of a 'very major' error cannot be ascertained.

The likely cause of the 'major' error was the use of an antibiotic gradient susceptibility testing method with media (MHB) not adequately validated in microbiological studies. MHB agar has previously been used in agar dilution and Etest methodologies for other HACEK-group organisms (11-13). The Etest application guide recommends using either Brucella blood agar or Mueller-Hinton agar with $1 \%$ hemoglobin and $1 \%$ IsoVitalex (BD, USA) for HACEK organisms (14); however, the cited literature provides no data on the use of Mueller-Hinton agar for susceptibility testing of $\mathrm{C}$ hominis. Penicillinase or cephalosporinase production appeared to be unlikely based on a negative nitrocefin test. A subpopulation of $\mathrm{C}$ hominis with isolated resistance to cephalosporins due to specific penicillinbinding protein mutations (as has been described in Streptococcus pneumoniae [15]) was also considered to be unlikely given that the intermediate zones did not grow when subcultured to another agar plate and the repeated susceptibility testing using BMD did not show any evidence of resistance.

Returning to the case, the patient received six weeks of intravenous ceftriaxone following his aortic valve replacement, rather than a standard four-week course (8), because of his septic cerebral embolus. Repeat echocardiography demonstrated complete resolution of his perivalvular abscess and a properly functioning prosthetic aortic valve. His neurological symptoms continued to improve, although he still had residual left-sided numbness at three-month follow-up. This case highlights both the typical clinical presentation of endovascular infection with $\mathrm{C}$ hominis and the potential issues that may arise when performing susceptibility testing for fastidious organisms in the clinical microbiology laboratory.

ACKNOWLEDGEMENTS: The authors thank Dr Johann Pitout for his assistance in this case. 


\section{REFERENCES}

1. Clinical Laboratory Standards Institute. Methods for Antimicrobial dilution and disk susceptibility testing of infrequently isolated or fastidious bacteria; Approved Guideline - Second Edition. CLSI document M45-A2. Wayne: Clinical and Laboratory Standards Institute, 2010.

2. Steinberg JP, Burd EM. Other Gram-negative and Gram-variable bacilli. In: Mandell GL, Bennett JE, Dolin R, eds. Principles and Practice of Infectious Diseases, 7th edn. Philadelphia: Elsevier, 2010:3019.

3. Malani AN, Aronoff DM, Kauffman CA. Cardiobacterium hominis endocarditis: Two cases and a review of the literature. Eur J Clin Microbiol Infect Dis 2006;25:587-95.

4. Chambers ST, Murdoch D, Morris A, et al. HACEK infective endocarditis: Characteristics and outcomes from a large, multi-national cohort. PLoS One 2013;8:e63181.

5. Chentanez T, Khawcharoenporn T, Chokrungvaranon N, et al. Cardiobacterium hominis endocarditis presenting as acute embolic stroke: A case report and review of the literature. Heart Lung 2011;40:262-9.

6. Lena TS, De Meulemeester C. A case of infective endocarditis caused by $\mathrm{C}$. hominis in a patient with HLAB27 aortitis. Can J Neurol Sci 2009;36:385-7.

7. Wormser GP, Bottone EJ. Cardiobacterium hominis: Review of microbiologic and clinical features. Rev Infect Dis 1983;5:680-91.

8. Baddour LM, Wilson WR, Bayer AS, et al. Infective endocarditis: Diagnosis, antimicrobial therapy, and management of complications: A statement for healthcare professionals from the Committee on
Rheumatic Fever, Endocarditis, and Kawasaki Disease, Council on Cardiovascular Disease in the Young, and the Councils on Clinical Cardiology, Stroke, and Cardiovascular Surgery and Anesthesia, American Heart Association. Circulation 2005;111:394-434.

9. Le Quellec, Bessis D, Perez C, et al. Endocarditis due to $\beta$-lactamase-producing Cardiobacterium hominis. Clin Infect Dis 1994;19:994-5.

10. Lu PL, Hsueh PR, Hung CC, et al. Infective endocarditis complicated with progressive heart failure due to $\beta$-lactamase-producing Cardiobacterium hominis. J Clin Microbiol 2000;38:2015-7.

11. Maurissen W, Eyskens B, Gewillig M, et al. Beta-lactamase-positive Cardiobacterium hominis strain causing endocarditis in a pediatric patient with tetralogy of Fallot. Clin Microbiol News 2008;30:132-3.

12. Yagupsky P, Katz O, Peled N. Antibiotic susceptibility of Kingella kingae isolates from respiratory carriers and patients with invasive infections. J Antimicrob Chemother 2001;47:191-3.

13. Goldstein EJ, Cherubin CE, M Shulman. Comparison of microtiter broth dilution and agar dilution methods for susceptibility testing of Eikenella corrodens. Antimicrob Agents Chemother 1983;23:42-5.

14. Kugler KC, Biedenbach DJ, Jones RN. Determination of the antimicrobial activity of 29 clinically important compounds tested against fastidious HACEK group organisms. Diagn Microbiol Infect Dis 1999;34:73-6.

15. Smith AM, Botha RF, Koornhof HJ, Klugman KP. Emergence of a pneumococcal clone with cephalosporin resistance and penicillin susceptibility. Antimicrob Agents Chemother 2001;45:2648-50. 


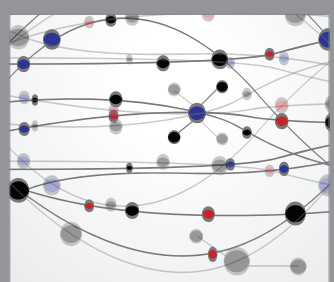

The Scientific World Journal
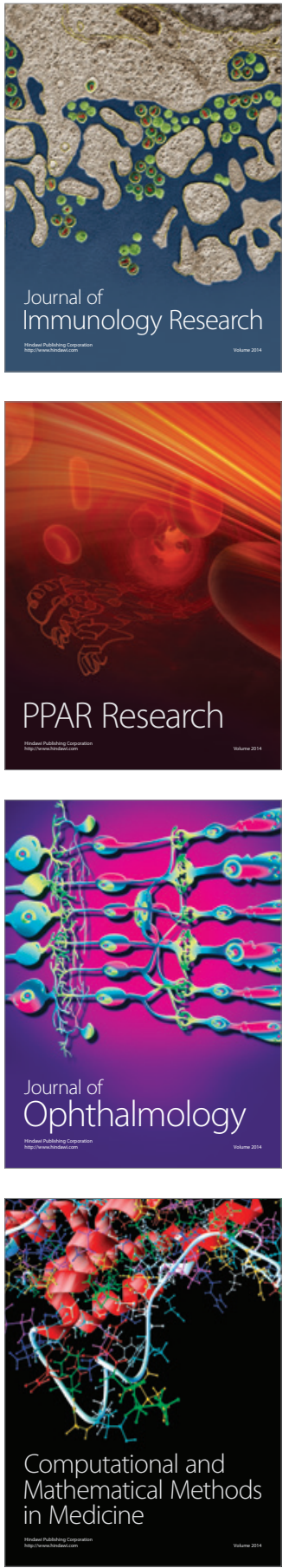

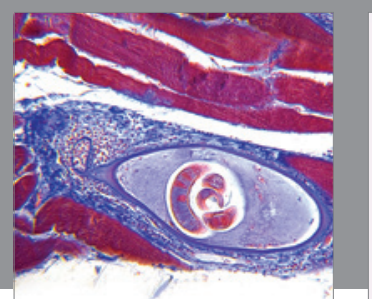

Gastroenterology Research and Practice

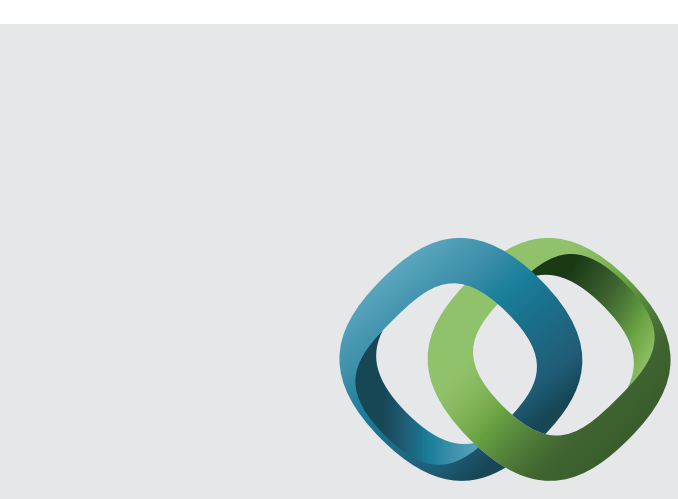

\section{Hindawi}

Submit your manuscripts at

http://www.hindawi.com
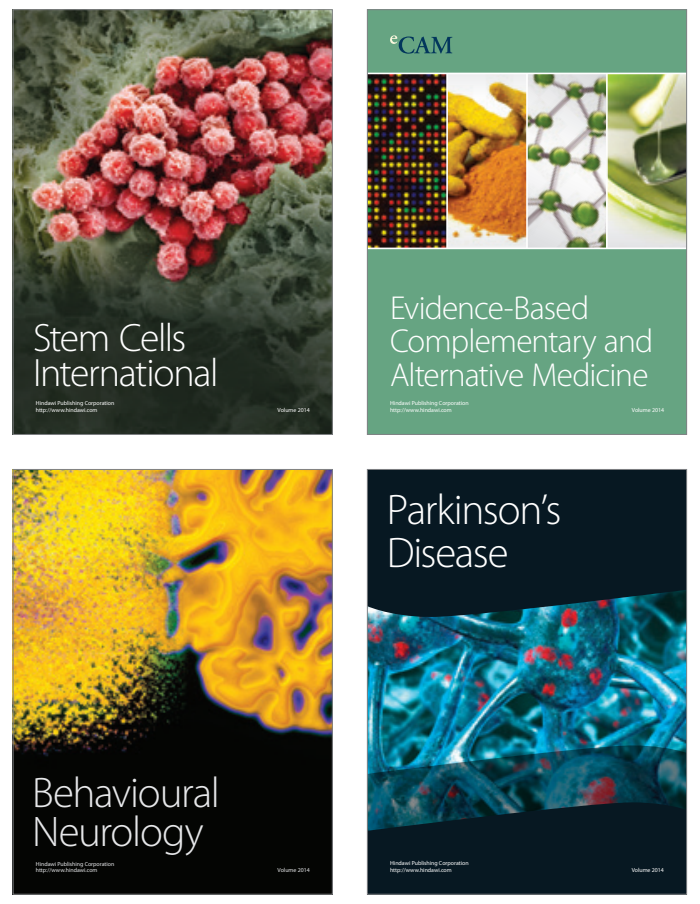
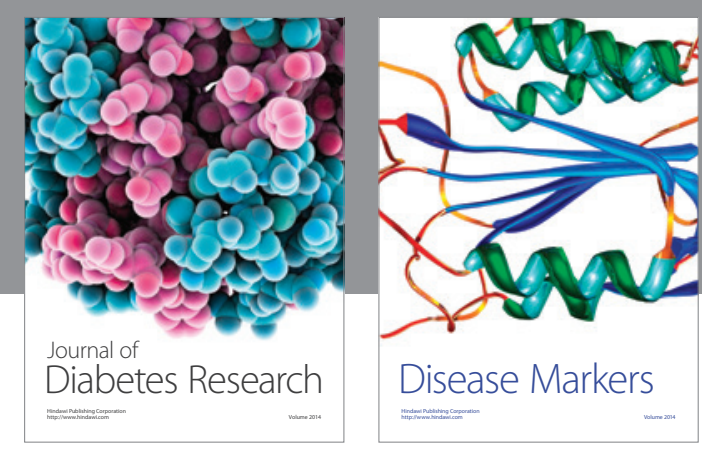

Disease Markers
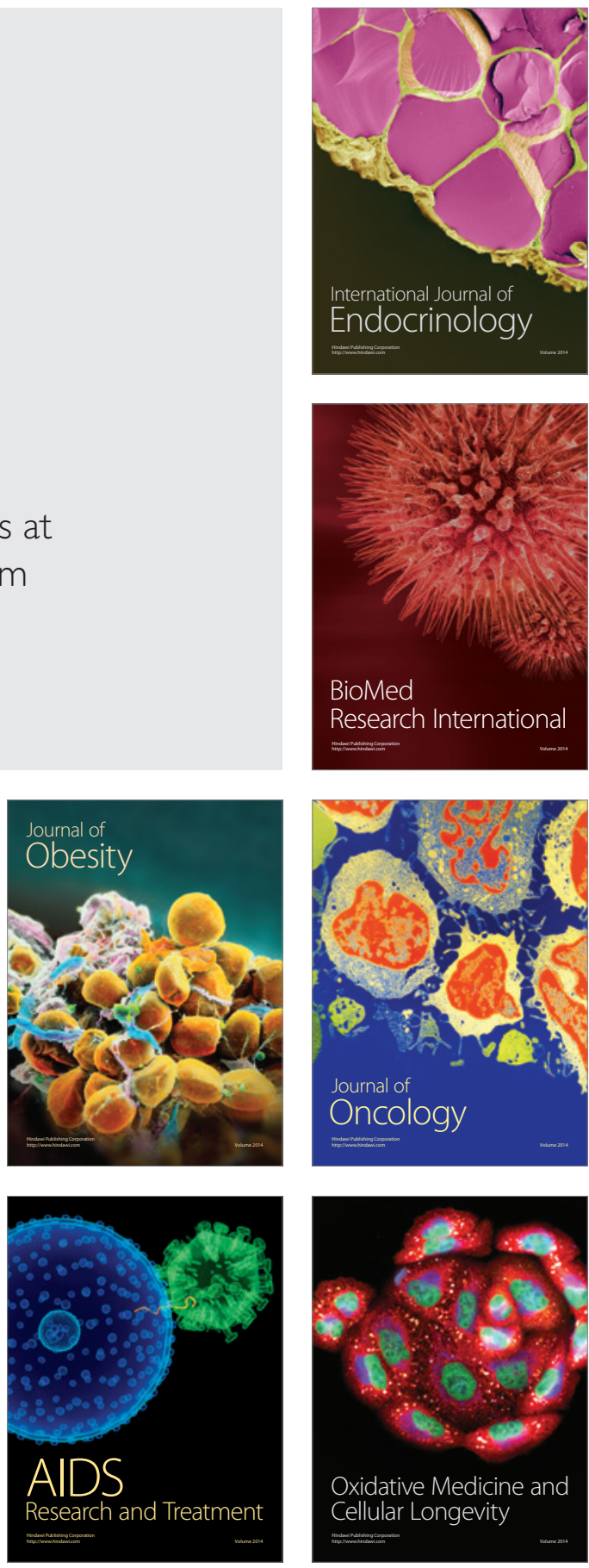